\title{
VALORIZATION OF MOROCCAN OLIVE STONES BY USING IT IN PARTICLEBOARD PANELS
}

\author{
M. Elbir ${ }^{1}$, A. Moubarik ${ }^{2 \wedge}$, E.M. Rakib ${ }^{3}$, N. Grimi ${ }^{4}$, A. Amhoud ${ }^{1}$, \\ G. Miguel ${ }^{5}$, H. Hanine 6 , J. Artaud ${ }^{7}$, P. Vanloot ${ }^{7}$ and M. Mbarki ${ }^{1}$
}

\begin{abstract}
The main objective of this work was to find new applications to valorize olive stones (endocarp and seed). In order to improve knowledge on olive stones, the phenolic compounds concentration of three varieties of Moroccan olive trees: Moroccan Picholine, Menara and Haouzian were studied. Olive stones of three varieties were characterized by Fourier Transform Mid Infrared Spectroscopy (FT-MIR). Total phenolic compounds are quantified after solid-liquid extraction by an assay of Folin-Ciocalteu. Moroccan Picholine stones (11.32 mg GAE/g DM) have a higher content of total phenolic compounds than Haouzia stones ( $4.55 \mathrm{mg}$ GAE/g DM) and Menara stones (3.56 mg GAE/g $\mathrm{DM})$. Thermogravimetric analysis indicates that up to $195^{\circ} \mathrm{C}$; there is no degradation of the stones. The biocide performance on agar-agar was tested with decay fungi. Biodegradation studies show that the most interesting results are obtained with Moroccan Picholine stones. The presence of Moroccan Picholine in a particleboard panels improves the total resistance of the particleboard panels against both Coriolus versicolor and Coniophora puteana rot fungi.
\end{abstract}

Keywords: Decay resistance; olive stone; particleboard; phenolic compounds.

\section{INTRODUCTION}

Oleaceae is a family comprising 600 species in 25 genera. Many of the genera are economically important such as the olive (Olea europaea) which is cultivated for its fruit and oil (Wallander and Albert 2000). The olive tree is among the oldest woody crops and is particularly widespread throughout the Mediterranean region and plays an important role in its rural economy, local heritage, and environment protection. The largest producing countries are located in the Mediterranean and Middle East regions providing $98 \%$ of the total cultivated surface area, and $99 \%$ of the total olive fruit production (Niaounakis and Halvadakis 2006, Besnard et al. 2011).

Olea europaea dried fruit has pharmacological properties, such as anti-bacterial, anti-viral, antiinflammatory activities and detoxification (Ding 1999). Such properties have been attributed to the presence of many compounds including phenols. Olive fruits are rich in phenolic compounds that represent 1 to $14 \%$ weight of dry pulp. The phenolic composition in the various parts of the fruit is complex depending on the variety, collection season, growing conditions, and time of ripening (Solinas et al. 1975, Vlahov 1992, Esti et al. 1998, Romani et al. 1999). Very few studies have

\footnotetext{
${ }^{1}$ Equipe Systèmes Chimiques Complexes, Faculty of Science and Technology, University Sultan Moulay Slimane. PB 523, Beni Mellal, Morocco. ${ }^{2}$ MAScIR-NANOTECH, ENSET, Avenue de l’Armée Royale, Madinat El Irfane, 10100 Rabat, Morocco.

${ }^{3}$ Laboratory of Organic and Analytical Chemistry, Faculty of Sciences and Technology, University Sultan Moulay Slimane., B.P 523, Beni-Mellal, Morocco.

${ }^{4}$ Université de Technologie de Compiègne EA 4297 TIMR, UTC/ESCOM, Centre de Recherche de Royallieu, B.P. 20529, 60205 Compiègne, France.

${ }^{5}$ Department of Biotechnology, University of Algarve, Faro, Portugal.

${ }^{6}$ Laboratoire de Valorisation et Sécurité des Produits Agro-alimentaires, Faculté des Sciences et Techniques, Université Sultan Moulay Slimane, B.P 523, Beni-Mellal, Morocco

${ }^{7}$ ISM2, UMR 6263, Equipe AD2EM, Université Paul Cézanne, case 451, 13397 Marseille Cedex 20, France.

Corresponding Author: ^amine.moubarik@yahoo.fr

Received: 07.02.2012 Accepted: 16.05.2012
} 
focused upon the phenolic composition of olive seeds, nevertheless some phenolic compounds have been identified including salidroside, nuzhenide, hydroxytyrosol, nuzhenide 11-methyl oleoside, oleuropein, tyrosol, and demethyloleuropein (Fig. 1) at all stages of maturation (Maestro-Durán et al. 1994, Servili et al.1999, Silva et al. 2010).

The olive stones and seeds are an important by-product generated in the olive oil extraction. Generally, this material is used as combustible to produce electric energy or heat. A large number of research articles have been published dealing with the chemical composition of olives and olive oil. However, only a few studies have been dedicated to analyzing the components and uses of the olive stone (Rodríguez et al. 2008).

The main objectives of this work are the extraction of phenolic compounds, the characterization (chemical, thermal and biological) and the valorization of Moroccan olive stones in particleboard panels.<smiles>OCCc1ccc(OCCOC2OC(CO)[C@H](O)C(O)C2O)cc1</smiles>

Tyrosol Hydroxytyrosol Salidroside

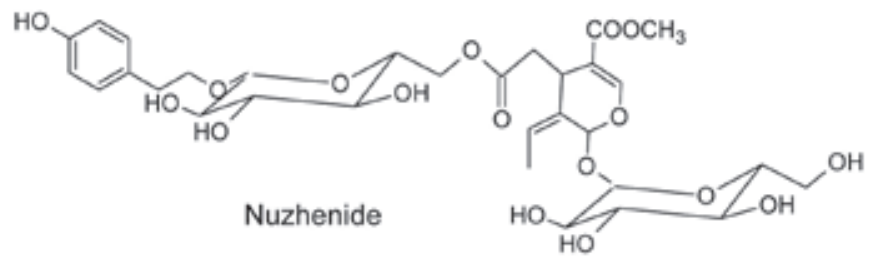

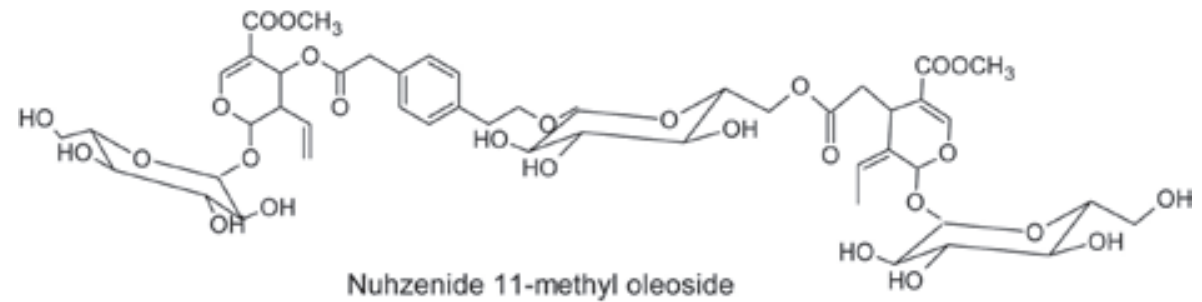

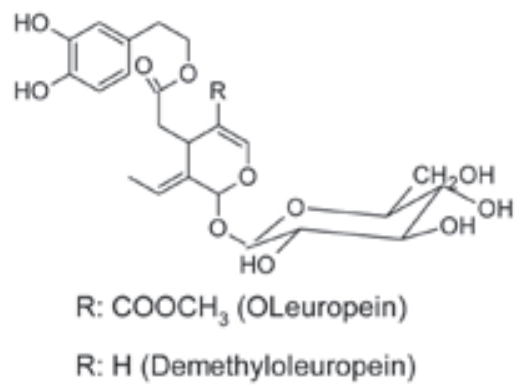

Figure 1. Some components found in stone and seed olives. 


\section{EXPERIMENTAL METHODS}

\section{Plant materials}

Mature olive fruits were obtained from the Moroccan Picholine variety, which grows widely in the province of Beni Mellal and from Menara and Haouzia varieties growing in the province of Marrakech of Middle Atlas and Marrakech-Tensift-Al Haouz (Morocco), respectively. Olive fruits were boiled (between 70 and $80^{\circ} \mathrm{C}$ ) in water for 8 minutes, and pulped by crushing them manually. Olive stones were then air dried on paper towels (2-4 days). After drying, the olive stones were ground (particle less than $0.5 \mathrm{~mm}$ ) in a knife mill "Retsch SK1".

Maritime pine (Pinus pinaster) particles was provided by the sawmill Ets. Labadie (Roquefort, France) Sd (moisture content around 8-10\%).

\section{Extraction and estimation of total phenolic compounds}

The solid-liquid extraction of total phenolic compounds was performed with a Soxhlet apparatus. Olive stone powder $(60 \mathrm{~g})$ was extracted in a Soxhlet apparatus, first with hexane $(500 \mathrm{ml})$ for 5 hours to remove lipids, then with acetone $(500 \mathrm{ml})$ for 5 hours and finally with ethanol $(500 \mathrm{ml})$ for 5 hours to remove total phenolic compounds (Rakib et al.2010).

Total phenols are estimated by Folin-Ciocalteu method (Singleton and Rossi 1965, Scalbert et al. 1989). A $2.5 \mathrm{ml}$ portion of Folin-Ciocalteu reagent and $2 \mathrm{ml}$ of a sodium carbonate solution $(75 \mathrm{~g} / \mathrm{l})$ are added to $0.5 \mathrm{ml}$ of the diluted extract. The assay tubes are kept $15 \mathrm{~min}$ in a water bath at $50^{\circ} \mathrm{C}$ and then transferred to cold water. The absorbance read was $760 \mathrm{~nm}$. A calibration curve with equation: $y=0.0021 x+0.0015\left(r^{2}=0.99\right)$ was constructed using gallic acid solutions within the range $10-100$ $\mathrm{mg} / \mathrm{l}$. Contents of total phenolic compound in olive stones were expressed as gallic acid equivalents in milligrams per gram dry matter (mg GAE/g, DM). The results were averages of triplicate analyses.

\section{Fourier Transform Middle-Infrared Spectroscopy (FT-MIR)}

Analyses were performed with FT-MIR. The spectra of the samples were recorded with a Perkin Elmer's FTIR (Spectrum One). Samples were deposited without preparation on attenuated total reflection (ATR) cell that is equipped by a diamond crystal. The crystal was cleaned between measurements by deionized water and dried by lint-free tissue. Spectra were recorded between 4000 and $600 \mathrm{~cm}^{-1}$, at $0.5 \mathrm{~cm}^{-1}$ nominal resolution.

\section{Thermogravimetric analysis (TGA)}

Thermogravimetric analysis (TGA) was used to determine the thermal stability and degradation of olive stones using a TGA Q50 thermogravimetric apparatus. Ten milligrams of each cured sample were placed on a balance located in the furnace and heat was applied over the temperature range from room temperature to $600^{\circ} \mathrm{C}$ at a heating rate of $5{ }^{\circ} \mathrm{C} / \mathrm{min}$ in air. Mass losses versus temperature thermograms were obtained showing the different decomposition processes.

\section{Particleboard preparation}

Single layer laboratory particleboards of dimension $350 \mathrm{~mm}$ x $310 \mathrm{~mm}$ x $14 \mathrm{~mm}$ were prepared from maritime pine (Pinus pinaster). The addition of the commercial Urea Formaldehyde (UF) resins to the particles was $7.5 \%$ based on solid mass; press time was $7.5 \mathrm{~min}$ at $195^{\circ} \mathrm{C}$ press platen temperature with a maximum specific pressure of $25 \mathrm{~kg} / \mathrm{cm}^{2}$. The UF resin had a density of 1280 $1290 \mathrm{~kg} / \mathrm{m}^{3}$, a $\mathrm{pH}$ of about $8.5-9$, and a viscosity of $350-600 \mathrm{mPa} . \mathrm{s}$, all measured at $20 \pm 2^{\circ} \mathrm{C}$; the 
gel time was $40-50$ seconds at $100^{\circ} \mathrm{C}$. The content of free formaldehyde is maximum $0.15 \%$ based on the liquid resin. The particles with size between 1 to $4 \mathrm{~mm}$ were dried to approx $2 \pm 0.5 \%$ moisture content prior to application of the resin. Each olive stone powder was ground and mixed at different concentrations (from 0 to $15 \%, \mathrm{w} / \mathrm{w}$ ) in particles. The target board density was $710 \mathrm{~kg}$ / $\mathrm{m}^{3}$. The particleboards were pre-conditioned at $25^{\circ} \mathrm{C}$ and $65 \%$ relative humidity in a Vötsch climate room for one week before testing.

\section{Biological properties}

\section{Decay test of the particleboard composites}

Particleboards composites measuring $20 \times 20 \times 14 \mathrm{~mm}^{3}$ were prepared for decay test, from Maritime pine (Pinus pinaster). A fungal decay test was done according to an adaptation of the standard EN 113 (AFNOR 1996) using a brown rot fungus, Coniophora puteana (BAM Ebw.15) and the white rot fungus, Coriolus versicolor (CTB 863A). A culture medium was prepared in Roux flasks. In each one, a nutritive medium, made up of a malt-agar mixture was placed ( $40 \mathrm{~g}$ of malt and $20 \mathrm{~g}$ of agar dissolved in $1000 \mathrm{ml}$ distilled water). After sterilization $\left(121^{\circ} \mathrm{C}\right.$ for $20 \mathrm{~min}$ at $\left.1 \mathrm{bar}\right)$, the Coriolus versicolor and Coniophora puteana were inoculated on culture medium in Petri dishes under sterile conditions. Then they were placed in constant conditions at $25^{\circ} \mathrm{C}$ and $65 \%$ relative humidity for 3 weeks to favour fungal development. After being conditioned at $25^{\circ} \mathrm{C}$ and $65 \%$ air moisture content, the particleboard composite samples were put into Petri dishes and exposed to Coriolus versicolor and Coniophora puteana for 16 weeks in darkness. Finally, test results were expressed as percentage of weight loss of composite panels due to fungal attacks after decay test using Equation (1) the measurement was done after drying of each sample). Ten replicates were used for each decay fungus. Weight loss was calculated as follows:

$$
\text { Weight loss (\%) }=\frac{\square m_{i} \square m_{f}}{m_{i}} \stackrel{\square}{\frac{1}{\dot{\dagger}}} \square 100
$$

Where $m_{i}$ and $m_{f}$ are the oven-dry weights of the sample before and after the decay test.

\section{Decay test of olive stone powders}

In order to confirm the fungicidal effect, olive stone powder was added to the culture medium. Each olive stone powder was ground and mixed at different concentrations (from 0 to $7 \%, \mathrm{p} / \mathrm{v}$ ) in malt-agar culture medium. After sterilization, the Coriolus versicolor and Coniophora puteana fungi were inoculated in the centre of the culture medium under sterile conditions. Then they were placed in constant conditions at $25^{\circ} \mathrm{C}$ and $65 \%$ relative humidity for 15 days to favour fungal development. The mean radius of the fungal development was measured. Test results were expressed as percentage of fungal development using Equation (2). Ten replicates were used for each fungal development.

$$
\text { Percentage of fungal development }(\%)=\frac{R_{1}}{R_{0}} \square 100
$$

Where

$R_{1}$ : is the mean radius of the fungal development after 15 days (olive stone powders present in Petri dishes).

$R_{0}$ : is the mean radius of the fungal development after 15 days (control: without presence of olive stone powder). 


\section{RESULTS AND DISCUSSION}

\section{Impact of olive stones varieties on polyphenols extraction}

Table 1 shows the polyphenols concentration in acetone and ethanol extracts. The results showed that Moroccan Picholine variety growing in the province of Beni Mellal had the higher contents of total phenolic compounds (11.32 mg/g DM), followed by Haouzia ( $4.55 \mathrm{mg} / \mathrm{g} \mathrm{DM})$ and Menara (3.56 $\mathrm{mg} / \mathrm{g} \mathrm{DM}$ ) variety. The relative amounts of phenols found in our experiment are in agreement with those already reported by some authors which described the lower levels of phenols in stones and seeds in comparison to the remaining tissues (pulp, leaves) of olives (Ryan et al. 2003). Nevertheless, compared with some other berries, the total phenolics contents in olive stones (3.56-11.32 mg/g DM) are higher than those of Oregon canberries (4.95-9.80 mg/g DM) berries (Wada and Ou 2002) and bayberries (3.60-4.46 mg/g DM) (Zhongxiang et al. 2007).

Table 1. Polyphenol contents of various olive stones. Three replicates of each sample.

S.D: standard deviation.

\begin{tabular}{ccccc}
\hline & \multicolumn{2}{c}{ Extraction methods } & \\
\cline { 2 - 3 } Olive varieties & $\begin{array}{c}\text { Ethanol extract } \\
(\text { mg GAE/g DM }) \\
\text { Mean } \pm \text { S.D }\end{array}$ & $\begin{array}{c}\text { Acetone extract } \\
(\text { mg GAE/g DM }) \\
\text { Mean } \pm \text { S.D }\end{array}$ & $\begin{array}{c}\text { Total phenolics } \\
\text { (mg GAE/g DM })\end{array}$ \\
\hline Moroccan Picholine & $3.07 \pm 0.007$ & $8.25 \pm 0.023$ & 11.32 \\
\hline Menara & $1.86 \pm 0.001$ & $1.70 \pm 0.002$ & 3.56 \\
\hline Haouzia & $2.15 \pm 0.003$ & $2.40 \pm 0.015$ & 4.55 \\
\hline
\end{tabular}

FT-MIR spectroscopy can be used to address qualitative and quantitative analyses. In this view, comparison with literature data provides preliminary information for the compositional characterization of FT-MIR bands of olives stones samples. Spectra of different olives stones are presented in figure 2. For the three varieties the spectra seem very similar. By means of FT-MIR spectroscopy, the original structure of different polyphenols can be clearly distinguished. The peak around $1285 \mathrm{~cm}^{-1}$ indicates a characteristic feature for the flavonoid-based tannins. This peak was assigned to the ethereal C-O stretching vibration (Socrates, 2001, Edelmann and Lendl 2002) arising from the pyran-derived ring structure of this class of tannins. Two broader peaks at around 1350 $\mathrm{cm}^{-1}$ and between 1290 and $1150 \mathrm{~cm}^{-1}$ can be observed in the spectra of gallic acid, tannic acid (gallotannin) and in the ellagitannin preparation with shifts in exact peak position and deviations in peak shape. Both peaks can be assigned to the combination of $\mathrm{C}-\mathrm{O}$ stretching and $\mathrm{O}-\mathrm{H}$ deformation vibrations (Socrates 2001, Edelmann and Lendl 2002). 


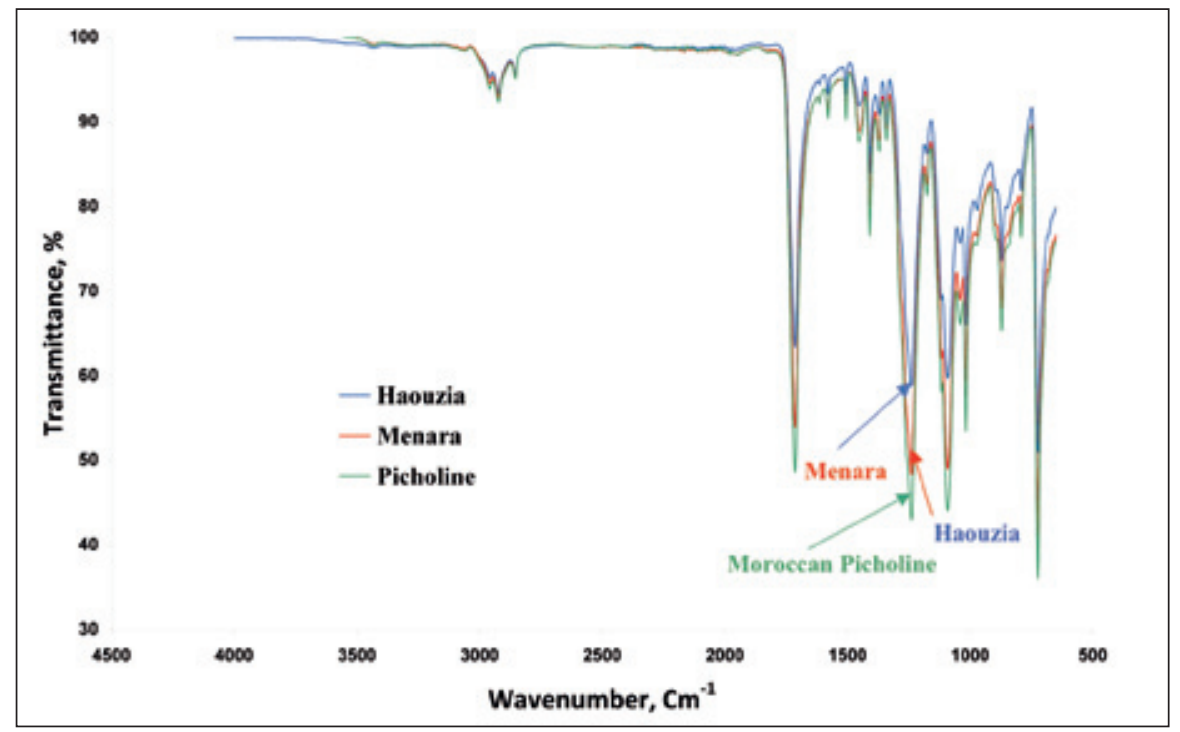

Figure 2. IR spectra of Haouzia, Menara and Moroccan Picholine olive stones.

\section{Thermal study of different olive stones}

Thermogravimetric analysis can check the thermal decomposition and thermal stability of the olive stones. Figure 3 shows the TGA curve of the Moroccan Picholine, Menara and Haouzia varieties in air atmosphere at a heating rate of $5^{\circ} \mathrm{C} / \mathrm{min}$, result that matches to typical findings for the decomposition of other lignocellulosic materials. Two steps can be differentiated in the TGA curves: I- Up to $200^{\circ} \mathrm{C}$, the weight loss corresponds to moisture release; II- The main weight loss takes place between 200 and $400^{\circ} \mathrm{C}$. In this temperature range, two decomposition processes are well defined, with maximum weight loss rates appearing at 245 and $330^{\circ} \mathrm{C}$. The first step can be attributed to the group of reactions involved in hemicellulose degradation (Órfão et al. 1999, Williams and Besler 1993), and the second one to those related to the thermal decomposition of cellulose (Órfão et al. 1999, Williams and Besler 1993).

The curve also shows that thermal degradation began to occur only after the materials have absorbed certain amounts of heat energy. Heat initiated the degradation processes and the breakdown of the structure by causing molecular chain ruptures. The results obtained with thermogravimetric analysis confirm that at $195^{\circ} \mathrm{C}$ they risk no degradation of the olive stones. 


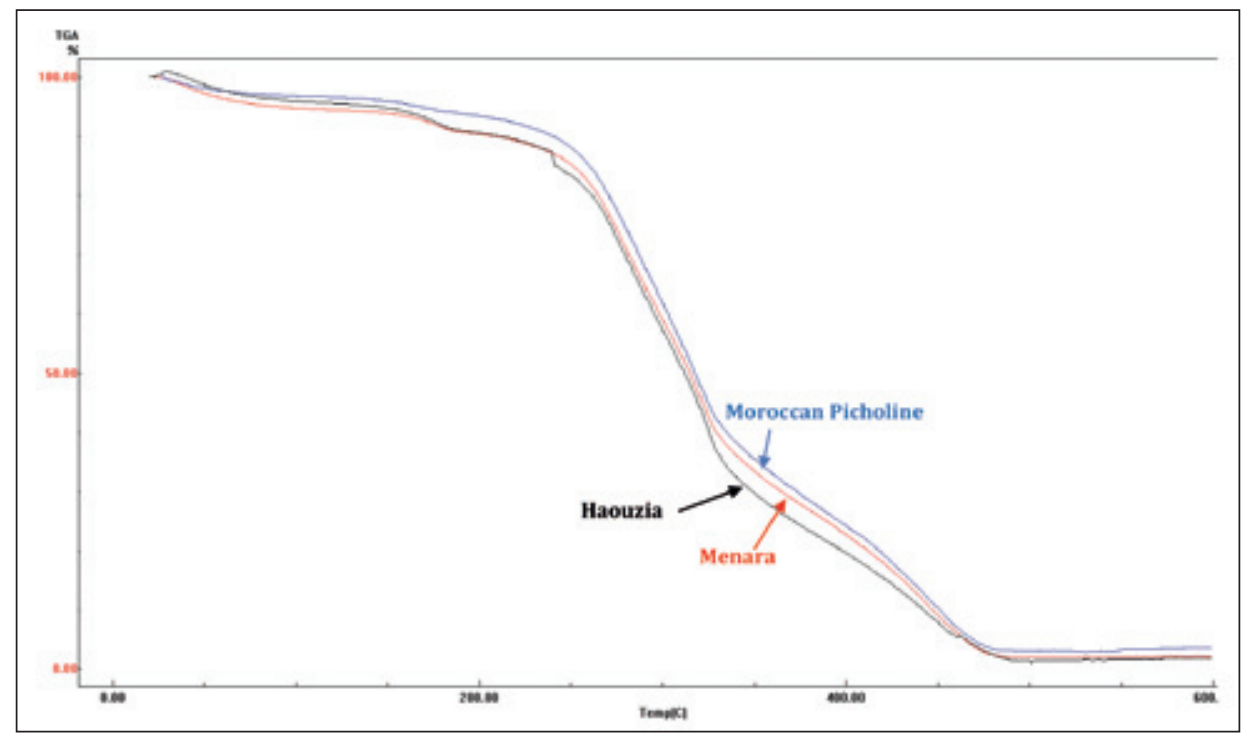

Figure 3. TGA graphical analysis for Menara, Haouzia and Moroccan Picholine olive stone varieties

\section{Decay resistance of the particleboard composites}

Weight losses of the particleboard composites caused by fungal decay after 16 weeks are shown in table 2. We can see that the control particleboard was attacked by both decay fungi (Coriolus versicolor and Coniophora puteana) with weight losses near $40 \%$. This proves that the fungus was virulent and the test of durability was valid according to the relevant European Norm 113 (EN 113, 1996). The values of weight losses for all other particleboard panels decreased. Laboratory tests have shown that the addition of olive stones $(5,10$ and $15 \%)$ is very effective in preventing attack by both decay fungi. We also observed that particleboard with Moroccan Picholine (5, 10 or 15\%) showed considerable resistance to both the decay fungi compared with particleboard with Haouzia $(5,10$ or $15 \%)$ and Menara (5, 10 or 15\%).

Results in table 2 seem to indicate that Coniophora puteana could be more efficient in wood degradation than Coriolus versicolor. This may be due to the differences between their decay mechanisms. This tendency has been previously observed by Nemli et al. (2006) and Moubarik et al. (2009). 
Table 2. Weight loss of composite in presence of olive stones after exposure to both decay fungi (Coriolus versicolor and Coniophora puteana). Ten replicates of each decay fungus.

S.D: standard deviation.

\begin{tabular}{clcc}
\hline \multirow{2}{*}{$\begin{array}{c}\text { Olive } \\
\text { varieties }\end{array}$} & \multicolumn{1}{c}{ Samples } & \multicolumn{2}{c}{ Weight loss (\%) } \\
\cline { 2 - 4 } & \multicolumn{1}{c}{$\begin{array}{c}\text { Coriolus versicolor } \\
\text { Mean } \pm \text { S.D }\end{array}$} & $\begin{array}{c}\text { Coniophora puteana } \\
\text { Mean } \pm \text { S.D }\end{array}$ \\
\hline \multirow{2}{*}{ Moroccan } & particleboard + 0\% (Control) & $35 \pm 3.1$ & $41 \pm 2.8$ \\
Picholine & particleboard + 5\% & $24 \pm 5.2$ & $28 \pm 3.6$ \\
& particleboard + 10\% & $19 \pm 4.1$ & $23 \pm 2.5$ \\
& particleboard + 15\% & $12 \pm 2.2$ & $18 \pm 3.7$ \\
\hline \multirow{3}{*}{ Menara } & particleboard + 0\% (Control) & $35 \pm 3.1$ & $41 \pm 2.8$ \\
& particleboard + 5\% & $32 \pm 4.4$ & $37 \pm 3.2$ \\
& particleboard + 10\% & $27 \pm 5.1$ & $33 \pm 4.7$ \\
& particleboard + 15\% & $22 \pm 3.7$ & $28 \pm 3.7$ \\
\hline \multirow{3}{*}{ Haouzia } & particleboard + 0\% (Control) & $35 \pm 3.1$ & $41 \pm 2.8$ \\
& particleboard + 5\% & $30 \pm 5.1$ & $35 \pm 5.2$ \\
& particleboard + 10\% & $25 \pm 6.2$ & $30 \pm 4.9$ \\
& particleboard + 15\% & $19 \pm 4.7$ & $25 \pm 3.6$ \\
\hline
\end{tabular}

\section{Fungicide effect of olive stones}

Table 3 shows the effect of olive stones (Picholine, Haouzia and Menara) concentration on fungal development. A decrease in fungal development for both decay fungi Coriolus versicolor and Coniophora puteana is observed on incorporation of olive stones into the culture medium. The results in table 3 confirm the fungicide effect of olive stones that contributes to improve the total resistance of the particleboard composites.

Hart and Hillis (1972) have demonstrated that the presence of phenolic compounds improves the durability of wood. Further studies evaluating the fungicide effect of phenolic compounds (tannins) also confirmed this activity (Pizzi and Conradie 1986, Charrier et al. 1995, Aloui et al. 2004, Cornelius et al. 2004, Moubarik et al. 2009).

Table 3. Effect of olive stone concentrations on fungus development.

Ten replicates of each fungal development. S.D: standard deviation.

\begin{tabular}{cccc}
\hline \multirow{2}{*}{ Olive varieties } & Concentration (\%) & \multicolumn{2}{c}{ Percentage of fungus development (\%) } \\
\cline { 2 - 4 } & & $\begin{array}{c}\text { Coriolus versicolor } \\
\text { Mean } \pm \text { S.D }\end{array}$ & $\begin{array}{c}\text { Coniophora puteana } \\
\text { Mean } \pm \text { S.D }\end{array}$ \\
\hline \multirow{3}{*}{ Moroccan Picholine } & 0 & $100 \pm 0$ & $100 \pm 0$ \\
& 2 & $20 \pm 0.5$ & $25 \pm 0.7$ \\
Menara & 5 & $6 \pm 0.1$ & $8 \pm 1$ \\
& 7 & $1 \pm 0$ & $3 \pm 0.3$ \\
& 0 & $100 \pm 0$ & $100 \pm 0$ \\
& 5 & $29 \pm 1.1$ & $31 \pm 1.4$ \\
Haouzia & 7 & $14 \pm 0.9$ & $17 \pm 1.1$ \\
& 0 & $7 \pm 0.2$ & $9 \pm 0.4$ \\
& 2 & $100 \pm 0$ & $100 \pm 0$ \\
& 5 & $26 \pm 0.9$ & $28 \pm 1.7$ \\
& 7 & $12 \pm 1.1$ & $7 \pm \pm 1.2$ \\
\hline
\end{tabular}




\section{CONCLUSION}

The present work proposes an innovative valorization of olive stones for particleboard production. The result of polyphenols extraction from Moroccan Picholine variety growing in the province of Beni Mellal had the higher contents of total phenolic compounds (11.32 mg/g DM), followed by Haouzia $(4.55 \mathrm{mg} / \mathrm{g} \mathrm{DM})$ and Menara $(3.56 \mathrm{mg} / \mathrm{g} \mathrm{DM})$ variety. The thermogravimetric analysis shows no significant degradation of the three olive stones varieties at temperature less than $195^{\circ} \mathrm{C}$. A good correlation was observed between the resistance to fungi and the concentration of olive stones. A decrease in fungal development for both decay fungi Coriolus versicolor and Coniophora puteana is observed after olive stones incorporation into the culture medium. The results of the present work contribute to the valorization of olive stones in the Mediterranean countries and especially in Morocco that has an ambitious agricultural strategy called «Green Morocco».

\section{ACKNOWLEDGMENT}

The authors would like to thank the INRA (Beni Mellal and Marrakech) for their olives collection.

\section{REFERENCES}

Aloui, F.; Ayadi, N.; Charrier, F.; Charrier, B. 2004. Durability of European oak (Quercus petraea and Quercus robur) against white rot fungi (Coriolus versicolor): relations with phenol extractives. Holz als Roh- und Werkstoff 62(4):286-290.

Besnard, G.; Hernández, P.; Khadari, B.; Dorado, G.; Savolainen, V. 2011. Genomic profiling of plastid DNA variation in the Mediterranean olive tree. BMC Plant Biology. 11:80p.

Charrier, B.; Haluk, J. P.; Klumpers, J.; Janin, G. 1995. Characterisation of European oak wood constituents acting in the brown discoloration during kiln drying. Holzforschung 49(2): 168-172.

Cornelius, M. L.; Bland, J. M.; Daigle, D. J.; Williams, K. S.; Lovisa, M. P.; Connick, W. J. Jr.; Lax, A. R. 2004. Effect of a lignin-degrading fungus on feeding preferences of formosan subterranean termite (Isoptera: Rhinotermitidae) for different commercial lumber. Journal of Economic Entomology 97(3):1025-1035.

Ding, B.P. 1999. Pharmacology of Qingguo pills on relieving cough. China Traditional Patent Medicine 21: 27-28.

Edelmann, A.; Lendl, B. 2002. Toward the optical tongue: Flowthrough sensing of tannin-protein interactions based on FTIR spectroscopy. Journal of the American Chemical Society 124(49):1474114747.

Esti, M.; Cinquanta, L.; la Notte, E. 1998. Phenolic compounds in different olive varieties. Journal of Agriculture and Food Chemistry 46(1):32-35.

EN 113. European Committee for Standardization. 1996. Wood preservatives- Test method for determining the protective effectiveness against wood destroying basidiomycetes- Determination of toxic values. Brussels, Belgium

Hart, J. H.; Hillis, W.E. 1972. Inhibition of wood-rotting fungi by ellagitannins in the heartwood of Quercus alba. Phytopathology 62: 620-626. 
Maestro-Durán, R.; Cabello, L.R.; Gutiérrez, R.V.; Roncero, V.A. 1994. Glucósidos fenólicos amargos de las semillas del olivo (Olea europaea). Grasas y Aceites 45(5):332-335.

Moubarik, A.; Charrier, B.; Charrier, F.; Pizzi, A.; Allal, A. 2009. Evaluation of decay resistance of wood products made from borax-impregnated wood and bonded with a formaldehyde-free cornstarch and tannin adhesive. Annals of Forest Science 66(1): 6p.

Nemli, G.; Gezer, E.d.; Yidiz, S.; Temiz, A.; Aydin, A. 2006. Evaluation of the mechanical, physical properties and decay resistance of particleboard made from particles impregnated with Pinus brutia ark extractives. Bioresource Technology 97(16):2059-2064.

Niaounakis, M.; Halvadakis, C. P. 2006. Olive processing waste management: Literature Review and Patent Survey 2nd Edition. Elsevier, Hardbound, ISBN: 0-08-044851-8, USA.

Órfão, J. J. M.; Antunes, F. J. A.; Figueiredo, J. L. 1999. Pyrolysis kinetics of lignocellulosic materials three independent reactions model. Fuel 78(3):349-358.

Pizzi, A.; Conradie, W.E. 1986. A chemical balance/microdistribution theory-new CCA formulation for soft-rod control. Material und Organismen 21: 31-46.

Rakib, M.; Chicha, C.; Abouricha, S.; Alaoui, M.; Bouli, A.; Hansali, A.; Owen, R. 2010. Determination of phenolic composition of carob pods grown in different regions of Morocco. Journal of Natural Products 3:134-140.

Rodríguez, G.; Lama, A.; Rodríguez, R.; Jiménez, A.; Guillén, R.; Fernández-Bolaños, J. 2008. Olive stone and attractive source of bioactive and valuable compounds. Bioresource Technology 99(13):5261-5269.

Romani, A.; Mulinacci, N.; Pinelli, P.; Vincieri, F.F.; Cimato, A. 1999. Polyphenolic content in five Tuscany cultivars of Olea europaea L. Journal of Agriculture and Food Chemistry 47(3):964-967.

Ryan, D.; Prenzler, P.D.; Lavee, S.; Antolovich, M.; Robards, K. 2003. Quantitative changes in phenolic content during physiological development of the olive (Olea europaea) cultivar Hardy's Mammoth. Journal of Agricultural and Food Chemistry 51(9): 2532-2538.

Scalbert, A.; Monties, B.; Janin, G. 1989. Tannins in wood: comparison of different estimation methods. Journal of Agricultural and Food Chemistry 37(5):1324-1329.

Servili, M.; Baldioli, M.; Selvagini, R.; Macchioni, A.; Montedoro, G. 1999. Phenolic compounds of olive fruit: one- and two-dimensional nuclear magnetic resonance characterization of nüzhenide and its distribution in the constitutive parts of fruit. Journal of Agricultural and Food Chemistry 47(1):12-18.

Silva, S.; Gomes, L.; Leitão, F.; Bronze, M.; Coelho, A.V.; Villas-Boas, L. 2010. Secoiridoids in olive seed: characterization of nüzhenide and 11-methyl oleosides by liquid chromatography with diode array and mass spectrometry. Grasas y Aceites 61(2): 157-164.

Singleton, V.L.; Rossi, J. A. 1965. Colorimetry of total phenolics with phosphomolybdicphosphotungstic acid reagents. American Journal of Enology and Viticulture 16(3):144-158. 
Socrates, G. 2001. Infrared and Raman Characteristic Group Frequencies: Tables and Charts; Wiley: Chichester, UK, ed. $3^{\mathrm{a}}$.

Solinas, M.; di Giovacchino, L.; Cucurachi, A. 1975. I polifenoli delle olive e dell'olio di oliva. Ann. Ist. Sperimen. Elaiotec 5:105-126.

Vlahov, G. 1992. Flavonoids in three olive (Olea europaea L.) fruit: varieties during maturation. Journal of the Science and Food Agriculture 58(1):157-159.

Wada, L.; Ou, B. 2002. Antioxidant activity and phenolic content of Oregon caneberries. Journal of Agricultural and Food Chemistry 50(12):3495-3500.

Wallander, E.; Albert, V.A. 2000. Phylogeny and classification of Oleaceae based on RPS16 and TRNL-F sequence data. American Journal of Botany 87(12):1827-1841.

Williams, P.T.; Besler, S. 1993. The pyrolysis of rice husks in a thermogravimetric analyzer and static batch reactor. Fuel 72(2):151-159.

Zhongxiang, F.; Min, Z.; Linxiang, W. 2007. HPLC-DAD-ESIMS analysis of phenolic compounds in bayberries (Myrica rubra Sieb. et Zucc.). Food Chemistry 100(2): 845-852. 
